\title{
Violência no trabalho: possíveis relações entre assaltos e TEPT em rodoviários de uma empresa de transporte coletivo
}

\author{
Camila Renata da Silva Alves ${ }^{1}$ e Patrícia Pinto de Paula ${ }^{2}$ \\ Instituto de Psicologia da Pontifícia Universidade Católica de Minas Gerais
}

\begin{abstract}
O objetivo principal do estudo foi investigar o possível nexo causal existente entre violência urbana (especificamente os assaltos) presente no contexto de trabalho dos rodoviários (motoristas e cobradores) de uma empresa de transporte coletivo da região metropolitana de Belo Horizonte (RMBH) e o adoecimento psíquico dos trabalhadores. A pesquisa de campo baseou-se no método qualitativo, ao realizarmos entrevistas semi-estruturadas com 16 rodoviários vítimas de assalto no contexto de trabalho e observação participante junto a linhas de ônibus consideradas mais vulneráveis a assaltos em uma cidade da RMBH. Os resultados da nossa pesquisa evidenciam que os rodoviários participantes do estudo apresentam sintomas isolados de transtorno de estresse pós-traumático (TEPT), sendo que alguns podem se tornar vulneráveis ao desenvolvimento do quadro desse transtorno se continuarem expostos a assaltos, principalmente em situação de reincidência. Em todos os participantes identificamos falas ilustrativas de pelo menos um dos sintomas de cada critério diagnóstico. Os sintomas relatados foram: revivência do assalto em pensamentos, imagens e sonhos; sofrimento psicológico decorrente do contato com indícios externos que simbolizam ou trazem a recordação de algum aspecto do trauma; evitação de pessoas que lembram o trauma; insônia e irritabilidade. Os resultados indicam possível nexo causal entre a situação de assalto sofrida durante a jornada de trabalho e o desenvolvimento de TEPT no rodoviário.
\end{abstract}

Palavras-chave: Trabalho do rodoviário, Violência urbana, Transtorno de estresse pós-traumático.

Violence in the work: the possible relationships between assaults and PTSD in drivers and conductors from a public transport company

The study's main objective was to investigate the possible existing causal connection among urban violence (specifically the assaults) present on the context of work of drivers and conductors from a public transport company of the metropolitan area of Belo Horizonte City (RMBH) and the psychological sickness of the workers. The field research based on the qualitative method, when we carried out semi-structured interviews with 16 workers, victims of assaults on the work context, and with participant observation next to bus lines considered more vulnerable to assaults in a city of the RMBH. The results show up that the drivers, participant of the study, present isolated symptoms of post-traumatic stress disorder (PTSD), it being that some can become vulnerable to the developing of diagnosis of this disorder, it if they continue exposed to assaults, principally in situation of re-incidence. In all of the participants, we identified illustrative speeches in at least one of the symptoms of each criterion diagnosis. The identified symptoms were: re-experience of the assault in thoughts, images and dreams; psychological suffering resulting from the contact with external signs, which symbolize or bring the recollection of some aspect of the trauma; avoidance of people who remember the trauma; insomnia and irritability. Results indicate a possible causal connection among the situation of the assault suffered during the working day and the developing of PTSD in the driver and conductor.

Keywords: Driver and conductor work, Urban violence, Posttraumatic stress disorder.

\section{Introdução}

\begin{abstract}
pesquisa teve como tema a violência urbana presente no contexto de trabalho dos Irodoviários (motoristas e cobradores) e o adoecimento psíquico dos trabalhadores. Foi problematizada a seguinte questão: qual a possibilidade de desenvolvimento de transtorno mental em rodoviários de uma empresa de transporte coletivo da região metropolitana de Belo Horizonte (RMBH) vítimas de assaltos no contexto de trabalho?
\end{abstract}

1 Psicóloga.

2 Psicóloga. Professora do Instituto de Psicologia da Pontifícia Universidade Católica de Minas Gerais, Unidade São Gabriel. 
A partir da questão problematizada, o objetivo principal da pesquisa foi investigar o possível nexo causal existente entre a violência urbana (mais especificamente a modalidade assalto) presente no contexto de trabalho dos rodoviários de uma empresa de transporte coletivo da RMBH e seu adoecimento psíquico. A pesquisa foi realizada de janeiro a junho de 2006 em duas etapas. Na primeira etapa foi feita a coleta de dados empíricos e, na segunda, realizou-se pesquisa teórica e análise dos dados.

A coleta de dados empíricos baseou-se no método qualitativo de pesquisa. Nessa etapa foram feitas entrevistas semi-estruturadas e observação participante. O campo de pesquisa foi uma empresa de transporte coletivo da RMBH. A empresa pesquisada é de médio porte e possui um total de 449 funcionários, sendo que desses, 246 são motoristas e 136 são cobradores. A empresa tem uma frota composta por 124 veículos que fazem itinerários que ligam os bairros da cidade de Belo Horizonte à cidade da região metropolitana onde se realizou o estudo.

Com vistas a compreendermos todo o contexto de trabalho do rodoviário e também da empresa empregadora, realizamos entrevistas semi-estruturadas com sujeitos representantes desse contexto. Foram feitas nove entrevistas com nove motoristas (seis motoristas de microônibus e três motoristas de ônibus convencional) e sete cobradores, todos empregados e vítimas de assaltos no contexto laboral. Realizaram-se entrevista com dois gerentes, gerente executivo e gerente de tráfego, representantes da linha de comando da empresa frente aos rodoviários.

No nível técnico entrevistou-se o médico do trabalho e a psicóloga da empresa. Também foi realizada uma entrevista com um representante do setor de saúde do sindicato da categoria. O foco da análise centrou-se nas dezesseis entrevistas com os rodoviários, por serem eles os sujeitos do estudo, entretanto, as demais entrevistas possibilitaram melhor compreensão do contexto e dinâmica de trabalho dos rodoviários.

A fim de aprofundar o conhecimento sobre o trabalho do rodoviário, utilizou-se a observação participante. Acompanhamos juntamente com motorista e cobrador uma viagem de duas linhas que atendem bairros de periferia da cidade. A escolha desses dois trajetos foi feita com base nas entrevistas realizadas, quando foi possível escutar as queixas de motoristas e cobradores quanto às linhas da empresa mais vulneráveis às práticas de assaltos durante as respectivas jornadas de trabalho.

A pesquisa teórica foi feita a partir do desdobramento da questão problematizada em categorias de análise tais como trabalho em transporte coletivo, violência urbana e transtornos mentais. Tomamos como categoria central de análise das entrevistas com os rodoviários o transtorno de estresse pós-traumático (TEPT) em razão desse transtorno ter seu desencadeamento associado a fatores traumáticos extremos. Segundo o DSM-IV (2002), o TEPT compõe o grupo dos chamados transtornos de ansiedade. A característica central desse transtorno é a manifestação de sintomas específicos após o contato direto ou indireto com um "estressor traumático extremo" (DSM-IV, 2002, p. 448). São considerados "estressores traumáticos extremos" contextos de guerra, desastres naturais e acontecimentos típicos da vida urbana, tais como sequestros e assaltos.

Trabalhando a maior parte do tempo nas ruas dos centros urbanos, os profissionais de transporte coletivo encontram-se potencialmente vulneráveis aos "estressores traumáticos extremos" de origem urbana, principalmente roubos e assaltos a mão armada ao longo de sua jornada de trabalho. Estamos, pois, considerando o assalto no contexto de trabalho como um "fator traumático extremo" que pode ou não desencadear o TEPT no rodoviário vítima de assalto durante a jornada de trabalho. A seguir o texto tratará dessa análise, buscando uma reflexão crítica sobre o tema. 


\section{O trabalho em transporte coletivo}

Segundo dados da Empresa de Transporte e Trânsito de Belo Horizonte S. A. (BHtrans, 2003), empresa que faz a gestão do transporte coletivo de Belo Horizonte, a capital mineira é a quarta capital do país, possui atualmente uma população de aproximadamente 2,4 milhões de habitantes e transporta diariamente 1,4 milhão de passageiros. Para atender a essa demanda diária, Belo Horizonte possui 300 linhas exploradas por 50 empresas de ônibus, com uma frota total de 2.874 veículos. Além dos ônibus convencionais (com motorista e cobrador) circulam em Belo Horizonte os ônibus suplementares (apenas com motorista), implementados desde 2001.

Segundo dados da Fundação João Pinheiro (2005), a RMBH atualmente é composta por 34 municípios. O Departamento de Estradas e Rodagem de Minas Gerais (DER-MG), além de ser responsável por todo o sistema rodoviário de Minas Gerais, planeja, gerencia e fiscaliza os serviços prestados pelas empresas de transporte coletivo das cidades da região metropolitana de Belo Horizonte.

Com o crescimento desenfreado das cidades, o transporte coletivo por ônibus tornou-se um serviço indispensável à maioria da população. Segundo a Fundação João Pinheiro (1996), a palavra "ônibus" deriva do latim omnibus, que significa "para todos". É esse "acesso democrático" que facilita a utilização do serviço como um meio de satisfação de necessidades básicas (Siqueira, 1996, citado por Almeida, 2002):

Nas grandes cidades, as oportunidades de consumo de alguns bens essenciais, ligados às condições de vida e aos direitos dos cidadãos como habitação, trabalho, saúde, educação e convívio social, dependem de outro serviço essencial que são os transportes disponíveis (p. 63).

Ainda de acordo com a Fundação João Pinheiro (1996), na época em que os bondes e auto-ônibus eram modalidades de transporte típicas do cenário urbano de Belo Horizonte, o trabalho em transporte coletivo era exercido tanto pelo motorneiro, como pelo condutor. $\mathrm{O}$ motorneiro era responsável por dirigir o veículo e o condutor, além de cobrar as passagens, controlava o trabalho do motorneiro, orientando-o sobre itinerários, paradas, velocidade do veículo e horários.

Após a extinção dos bondes e a evolução da modalidade de transporte auto-ônibus para ônibus, motorneiro e condutor passaram a se chamar, respectivamente, motorista e cobrador. Assim como em épocas passadas, atualmente o trabalho em transporte coletivo é resultado da parceria desses dois profissionais com funções distintas.

O motorista, além de ser responsável pela condução do ônibus, assume funções delegadas antigamente ao condutor, tais como controle de itinerários, paradas, velocidade do veículo e horários. O cobrador, como o próprio nome diz, continua tendo como função prioritária a cobrança das passagens. Essa parceira de trabalho acontece nos ônibus convencionais, ou seja, ônibus com motorista e cobrador. Nos microônibus (veículo no qual não existe a figura do cobrador), o motorista exerce dupla função, tanto de motorista, como de cobrador.

A jornada diária de trabalho dos motoristas e cobradores da empresa de transporte coletivo pesquisada dura em média seis horas e quarenta minutos. Esses trabalhadores ${ }^{3}$ têm um intervalo de vinte minutos na jornada de trabalho e uma folga semanal. Alguns trabalham como folguistas, o que a categoria chama de "tapa buraco", ou seja, cobrem folgas e, por isso, estão a cada dia em um horário e local diferentes. Outros trabalham como feristas, ou seja, cobrem férias, estando a cada mês em uma linha diferente. 
Durante a jornada, o motorista precisa ter, prioritariamente, muita atenção. $\mathrm{O}$ motorista precisa estar atento ao trânsito, cruzamentos, sinalizações e condições das vias públicas para evitar colisões com outros veículos ou atropelamento de pedestres. Também é fundamental que o motorista esteja atento ao embarque e desembarque de passageiros para não deixar ninguém para trás ou fora do ponto de desembarque.

A jornada de trabalho do motorista e do cobrador, em princípio, inicia-se e finaliza-se no ponto de partida do ônibus. O motorista que faz o primeiro itinerário do dia inicia a viagem do ônibus na garagem da empresa, porque tem que buscar o ônibus para começar o trabalho. Já o motorista que rende o anterior, ou seja, que dá continuidade ao itinerário, inicia sua jornada no ponto de partida. Tanto o motorista, quanto o cobrador precisam estar obrigatoriamente na empresa ou no ponto de partida minutos antes do ônibus iniciar o itinerário.

Antes de iniciar o itinerário, o cobrador recebe a papeleta do ônibus, organiza o dinheiro que leva para dar troco, troca o letreiro (em alguns casos o próprio motorista realiza essa tarefa), abre as janelas do ônibus e anota o número da roleta de entrada (número da roleta final do cobrador da jornada anterior). Esse número fica localizado na parte inferior da roleta e é o controle da quantidade de pessoas que entraram no ônibus e pagaram passagens. À medida que os passageiros "rodam" a roleta, esse número vai aumentando.

Durante a jornada de trabalho, além de cobrar as passagens, o cobrador é um auxiliar do motorista. O banco do motorista fica localizado no lado esquerdo do ônibus. Isso dificulta a visibilidade pelo espelho retrovisor direito. Para suprir essa deficiência, o auxílio do cobrador é fundamental, pois ele trabalha no lado direito do ônibus e, portanto, tem uma visão privilegiada desse ponto.

Essa visão privilegiada do lado direito facilita o auxílio do cobrador em conversões à direita, manobras, rés e ultrapassagens. Além desses auxílios, quando um passageiro desce do ônibus, o cobrador bate com uma moeda por duas vezes seguidas na roleta para sinalizar ao motorista que o passageiro já desceu e que, assim, a porta traseira pode ser fechada.

Além de cobrar as passagens e auxiliar o motorista, o cobrador também tem a função de dar informações aos passageiros com dúvidas sobre o itinerário, como, por exemplo, a localização do ponto onde precisam descer. Por isso, o cobrador precisa conhecer bem o itinerário para transmitir informações corretas aos passageiros.

Assim como o cuidado com o ônibus é responsabilidade do motorista, o dinheiro das passagens é de inteira responsabilidade do cobrador. Ao final de toda jornada de trabalho o cobrador organiza o dinheiro, separa e carimba os vales transportes e faz os devidos cálculos para preencher a papeleta do ônibus, que é um tipo de relatório da jornada de trabalho.

\section{Violência urbana no contexto de trabalho do rodoviário}

Atuando como um profissional do setor de serviços que exerce seu trabalho a maior parte do tempo "extramuros" da empresa, isto é, nas ruas, tem contato direto com um público imprevisível e transporta valores em dinheiro, o rodoviário está potencialmente vulnerável a certas modalidades de violência urbana, principalmente aos assaltos a mão armada. $\mathrm{O}$ contexto de trabalho do rodoviário tem especificidades bem representadas por Paes-Machado e Levenstein (2002):

Uma característica marcante do trabalho dos rodoviários é eles não atuarem em um ambiente fixo, fechado e protegido como os locais de trabalho situados em edificações [...] outra especificidade está relacionada com o contato estreito do rodoviário com um público 
volátil, que, possuindo como característica comum o uso do transporte, tem acesso indistinto ao interior dos veículos coletivos (p. 1218).

Segundo Caldeira (2001), os assaltos tornaram-se práticas comuns no transporte urbano intermunicipal e interestadual, configurando-se como um dos maiores problemas sociais da contemporaneidade. Pastana (2003, citada por Boschi, 2003) também aponta a emergência de tal problema nos centros urbanos afirmando que hoje "(...) os transportes públicos não se mostram como alternativa segura para o cidadão amedrontado" (p. 157). Vale destacar que a insegurança do cidadão usuário dos transportes públicos inclui o usuário passageiro como também o rodoviário, motorista e cobrador que se encontram no interior do veículo.

Os dados empíricos evidenciam a veracidade de tais afirmações. Segundo Caldeira (2001), o Rio de Janeiro é um dos estados mais acometidos pela epidemia de assaltos a ônibus, sendo que em 1999 foram registradas 7.683 ocorrências de assaltos a coletivos no estado.

Em Belo Horizonte e na região metropolitana, os assaltos a ônibus também tornaram-se acontecimentos frequentes no cotidiano dos rodoviários. Segundo reportagem do jornal $O$ tempo (2002), os "números do sindicato dos trabalhadores em transporte rodoviário de Belo Horizonte apontam que, em 2001 foram registrados 3.156 roubos a ônibus na capital e grande BH. Uma média de 8,6 ocorrências por dia" (p. 9).

Uma pesquisa feita pelo Sistema Estadual de Análise de Dados Estatísticos (SEADE) sobre as condições de saúde e segurança dos motoristas de transporte coletivo da região metropolitana de São Paulo (dados de 2000) e região metropolitana de Belo Horizonte (dados de 2002) revelou uma elevada incidência de violência no contexto de trabalho dos rodoviários de ambas as regiões (Costa, Koyama, Minuci \& Fischer, 2003). Segundo a pesquisa, os índices de violência (principalmente de assaltos a mão armada e agressões verbais) foram maiores na região metropolitana de Belo Horizonte. Os dados mostraram que 43,4\% dos motoristas mineiros já disseram ter sido vítimas de assaltos no ano anterior à pesquisa, contra 38,5\% dos motoristas paulistas. Em Belo Horizonte, após os assaltos a mão armada, as principais ocorrências registradas em 2002 envolvendo ônibus foram de agressão verbal (40\%), assalto sem arma $(7,4 \%)$ e agressão física $(6,8 \%)$.

Segundo dados de uma pesquisa feita em 2005 pela Fundação João Pinheiro, em parceria com Núcleo de Estudos em Segurança Pública da Universidade Federal de Minas Gerais (NESP), na RMBH as taxas de roubos a ônibus por 100 mil habitantes apresentaram crescimento em 2003 e uma breve queda em 2004. A taxa média de ocorrências em 2003 foi de 19,95 ocorrências por 100 mil habitantes. Em 2004, essa taxa foi reduzida para 14,17 ocorrências.

\section{Trabalho em transporte coletivo, violência urbana e transtornos mentais}

Segundo Mendes (1999), no Brasil, os estudos sobre os impactos das condições e da organização do trabalho na saúde física e mental dos rodoviários ainda são escassos e recentes em comparação com estudos feitos com outras categorias profissionais.

É importante ressaltar que, para Dejours (1992) as condições do trabalho englobam os agentes físicos, biológicos e químicos presentes no contexto de trabalho com consequência sobre a saúde física do trabalhador. Por sua vez, a organização do trabalho está vinculada a distribuição de poder, tarefas, hierarquias, responsabilidades, fatores que causam impacto na saúde psíquica do trabalhador. 
Tendo como enfoque as condições e a organização do trabalho dos rodoviários destacase a pesquisa feita em São Paulo por Souza (1996, citado por Almeida, 2002). Como dificuldades presentes nas condições de trabalho, os motoristas pesquisados pelo autor elencaram o intenso barulho provocado pelo motor do ônibus e a poluição. Como principais dificuldades relacionadas à organização do trabalho, os profissionais elencaram as responsabilidades financeiras, como pagamento de multas de trânsito, peças quebradas do ônibus e consertos oriundos de acidentes com o veículo. Os motoristas também queixaram-se da responsabilidade com manobras difíceis em trânsito intenso.

No Rio de Janeiro uma das pesquisas relevantes foi a realizada por Ramos (1991, citado por Mendes, 1999). Os dados coletados pelo autor revelaram que as principais deficiências das condições de trabalho correspondiam a péssima manutenção dos veículos, ausência de condições sanitárias satisfatórias e de pausas para descanso.

Almeida (2002) fez um levantamento, junto ao departamento de psicologia do Detran de Pernambuco, dos principais fatores "externos" e "internos" que comprometiam o desempenho profissional dos rodoviários de Recife. Entre os "fatores externos" surgiram questões como as exigências dos usuários, as condições das estradas, congestionamentos, temperatura do motor e poluição sonora. Como "fatores internos" apareceram as doenças crônicas e agudas, como deficiências na visão e audição, fadiga, estresse, problemas pessoais, abuso de álcool e disparidade entre a intensidade das exigências cognitivas do trabalho e o grau de escolaridade dos motoristas.

Em Belo Horizonte ganham destaque alguns estudos feitos sobre as condições e a organização do trabalho dos rodoviários. Nos anos 60 a modalidade de transporte coletivo "ônibus" vivenciou seu auge no cenário urbano de Belo Horizonte. Desde aquela época, proliferaram na imprensa notícias sobre greves de motoristas em protesto contra as condições e a organização do trabalho a que estavam submetidos. Segundo dados da Fundação João Pinheiro (1996), as principais queixas dos motoristas naquela época eram relativas às jornadas excessivas (de até 14 horas), sem direito a horas extras nem folgas semanais.

A Reportagem Ônibus, essa máquina de fazer neuróticos - publicada em 1969 no jornal Diário da Tarde e citada pela Fundação João Pinheiro (1996) - mostrou o resultado de um estudo feito sobre o contexto de trabalho dos profissionais do transporte coletivo de Belo Horizonte na década de 60. Segundo a reportagem o estudo evidenciou que aqueles trabalhadores "eram submetidos a condições estressantes, que abalavam os aspectos físicos e mentais devido ao trânsito cada vez mais intenso, à precária tecnologia do material rodante e às extensas jornadas de trabalho" (Fundação João pinheiro, 1996, p. 216).

Segundo a Fundação João Pinheiro (1996), nos anos 70 também foram realizados vários movimentos grevistas em protesto contra as condições e a organização do trabalho no transporte coletivo. Um dos principais movimentos grevistas ocorreu em 1979, quando motoristas reclamaram de alguns aspectos penosos presentes em seu contexto de trabalho, tais como a falta de horários para as refeições. Já nessa época a insegurança quanto a alguns passageiros e os riscos de assaltos apareciam nas queixas dos motoristas.

Outra pesquisa de destaque foi realizada por Waldvogel e Salim (2002), que fizeram uma análise dos acidentes de trabalho ocorridos com motoristas e cobradores de ônibus da região metropolitana de São Paulo (dados de 1997 e 1999) ${ }^{4}$ e da região metropolitana de Belo Horizonte (dados de 1998 e 2000). Mais especificamente com relação à RMBH, motoristas e cobradores totalizaram $21 \%$ dos acidentes de trabalho registrados no setor de transporte nos anos pesquisados, ficando atrás de motoristas de caminhões $(29,3 \%$ dos acidentes) e motociclistas (24,2\% dos acidentes). Os principais agentes causadores de acidentes foram meios

4 Além de motoristas e cobradores de ônibus, participaram da pesquisa outros profissionais do setor de transporte, tais como motoristas de caminhão, motociclistas, motoristas de carro forte, motoristas de carro particular, condutores de transporte coletivo sobre trilhos e motoristas de produção ou testes. 
de locomoção, quedas, objetos que atingiram os profissionais durante o trabalho e as agressões físicas.

No Brasil, estudos sobre o impacto da violência urbana presente no contexto de trabalho dos rodoviários sobre sua saúde mental ainda são pouco frequentes. Um dos estudos mais relevantes foi feito por França, Santos e Rubino (1998, citados por Paes-Machado \& Levenstein, 2002). Esses três autores realizaram uma pesquisa sobre o impacto dos assaltos na saúde mental de cobradores de uma empresa de transporte coletivo de Salvador. Os dados da pesquisa evidenciaram que $37,2 \%$ dos trabalhadores sentiam-se mais nervosos e preocupados e $30,3 \%$ assustavam-se com facilidade depois de terem vivenciado práticas de assalto no contexto de trabalho.

Galvão (1996, citado por Almeida, 2002) fez uma análise de 1.101 Comunicados de Acidente de Trabalho (CAT's) emitidos por empresas de transporte coletivo na cidade de São Paulo entre os anos de 1989 e 1995. A violência urbana no contexto de trabalho, representada por assaltos e agressões, apareceu como uma das causas dos acidentes de trabalho mais frequentes, totalizando $12 \%$ dos CAT's emitidos.

Uma pesquisa qualitativa feita por Paes-Machado e Levenstein (2002) com 130 rodoviários da região metropolitana de Salvador constatou a presença constante da violência no ambiente de trabalho da categoria, principalmente sob a forma de ameaças, agressões físicas e assaltos a mão armada. Essas modalidades de violência apresentaram-se como fatores potencialmente danosos para a saúde mental dos rodoviários pesquisados.

Esses autores conceituaram a violência urbana como um "evento traumático extremo". $\mathrm{Na}$ pesquisa com os rodoviários da região metropolitana de Salvador, constataram que "os sucessivos traumas experimentados pelos que trabalham em coletivo provocam ansiedade, transtornos do medo (...) O núcleo central está referido ao medo do desaparecimento físico" (p. 123). Os pesquisadores constataram sintomas de ansiedade em muitos rodoviários vítimas de assaltos, tais como sensibilidade aguda a ruídos e respostas de susto exageradas durante a jornada de trabalho. Como transtornos do medo, os pesquisadores denominaram a percepção alterada do ambiente de trabalho, pois os rodoviários vítimas de assalto declararam enxergar assaltantes nas figuras de passageiros comuns.

A já citada pesquisa feita pela fundação SEADE sobre as condições de saúde e segurança dos motoristas de transporte coletivo urbano da RMSP e RMBH trouxe dados relevantes sobre a violência urbana presente no contexto de trabalho e seu impacto na saúde desses profissionais. $81,8 \%$ dos motoristas belo-horizontinos e $78 \%$ dos motoristas paulistanos declararam trabalhar com medo de serem assaltados.

Segundo Costa et al. (2003), em Belo Horizonte, o medo de assalto aumenta em 72,6\% a chance de desenvolvimento de distúrbios gastrintestinais nos motoristas. Também foi constatado por esses autores que o medo de assalto aumenta em $65 \%$ a chance de desenvolvimento de quadros de estresses em motoristas de Belo Horizonte. É importante ressaltar que, sintomas de estresse foram detectados em 38,5\% dos motoristas pesquisados na capital mineira.

Pode-se dizer que, com base no levantamento bibliográfico realizado, a violência urbana encontra-se como uma das facetas altamente complexas da organização do trabalho dos rodoviários. Isso se dá pelo fato dos rodoviários serem "trabalhadores que exercem sua atividade profissional no espaço da rua, expostos à violência, aos problemas urbanos e aos riscos intrínsecos de seu trabalho diuturno" (Waldvogel \& Salim, 2002, p. 25).

Diante dessas evidências empíricas a pesquisa teve como foco de análise o assalto como elemento que se faz presente no contexto de trabalho dos rodoviários de uma empresa de transporte coletivo da RMBH. Propusemos a investigação sobre o assalto sofrido durante a jornada de trabalho como um fator danoso ou potencialmente danoso à saúde mental dos 
rodoviários, uma vez que esses assaltos podem significar um evento que se caracteriza como um "estressor traumático extremo", elemento constituinte do quadro de transtorno do estresse póstraumático. Segundo o DSM-IV (2002), o transtorno de estresse pós-traumático compõe o grupo dos chamados transtornos de ansiedade. A característica central desse transtorno é a manifestação de sintomas específicos após o contato direto ou indireto com um "estressor traumático extremo" (DSM-IV, 2002, p. 448), tais como situações como sequestros e assaltos.

O DSM-IV (2002) define quatro critérios diagnósticos para o quadro de TEPT. O primeiro critério diagnóstico é a vivência pessoal direta ou indireta de um ou mais "eventos estressores traumáticos extremos". A resposta do indivíduo a esses "estressores traumáticos extremos" é marcada por intenso medo, impotência ou horror.

O segundo critério diagnóstico para o quadro de TEPT é a revivência do "evento estressor traumático" em imagens, pensamentos ou percepções, sonhos aflitivos, alucinações, ilusões ou episódios de flashbacks dissociativos e sofrimento psicológico ou reatividade fisiológica no contato com indícios internos ou externos que simbolizam ou trazem a recordação de algum aspecto do trauma.

O terceiro critério diagnóstico para o quadro de TEPT é a evitação de estímulos que lembrem o evento traumático e o distanciamento de pessoas ou atividades significativas (não detectados antes do trauma), indicados pela presença de três ou mais dos seguintes sintomas: evitação de pensamentos, sentimentos, conversas, atividades, locais ou pessoas que lembrem o trauma; incapacidade de lembrar uma característica importante do trauma; redução do interesse por atividades significativas; distanciamento em relação a outras pessoas; redução na capacidade de ter sentimentos de carinho por outras pessoas; sentimento de uma vida breve.

O quarto critério diagnóstico para o quadro de TEPT engloba sintomas de excitabilidade acentuada (não detectados antes do trauma), indicados pela presença de dois ou mais destes sintomas: insônia, irritabilidade, baixa concentração, hipervigilância e resposta de sobressalto exagerada.

Esses critérios orientaram a análise dos dados das entrevistas com os rodoviários na medida em que a questão norteadora da pesquisa foi conhecer as possibilidades de desenvolvimento de transtorno mental em rodoviários vítimas de assaltos no contexto de trabalho. A hipótese construída foi de que rodoviários vítimas de assalto poderiam desenvolver sintomas de transtorno de estresse pós-traumático. Sendo assim, a violência urbana, mais especificamente a modalidade assalto, foi analisada como um possível "estressor traumático extremo" desencadeador de sintomas de transtorno de estresse pós-traumático nos rodoviários.

\section{Apresentação e análise dos resultados da pesquisa}

A frequência de assaltos aos rodoviários da empresa pesquisada tem aumentado, confirmando os indicadores sobre violência na RMBH. Na maioria dos assaltos relatados, um dos assaltantes rende o motorista, ameaçando-o com uma arma apontada para a cabeça e obrigando-o a permanecer com o ônibus parado ou a dirigir com a velocidade reduzida. O outro assaltante (também armado) ameaça o cobrador e obriga-o a entregar o dinheiro das passagens. Após o roubo, os assaltantes descem e ordenam ao motorista arrancar rapidamente. Esses aspectos dos assaltos podem ser ilustrados pela fala deste rodoviário:

(...) de um beco lá saiu dois camarada armado, meteu o revólver e falou: "pára o carro". Aí eu parei, ele puxou o cano do revólver pra trás, meteu na minha cabeça (...) e o outro foi pegar o dinheiro com o cobrador. Aí desceram e pediram que a gente puxasse o carro (Motorista 3). 
Os assaltos aos ônibus são feitos predominantemente por jovens do sexo masculino (entre 15 e 20 anos) armados e denominados pelos rodoviários de "ninjas" ou "jovens mal aparentados" (trajando chinelo, bermuda, jaqueta, tatuagem, brinco, boné ou toca na cabeça ou cabelo amarelado). Esses jovens abordam o ônibus em pontos próximos aos bairros de periferia ou dentro deles. Isso aparece na fala do rodoviário a seguir:

Bermuda, chapéu, óculos, já pensa e fala nossa, mais um assalto (...) dois, três, aquelas toca ninja, vinte e três horas em determinados pontos (Motorista 6).

O rodoviário tem que, por norma da empresa parar para todo passageiro que sinalize. Porém, a experiência do assalto faz com que os rodoviários identifiquem alguns perfis de passageiros como potencialmente ameaçadores, o que gera mais desgaste psíquico frente ao seguinte dilema: obedecer à regra da empresa e parar o ônibus para qualquer passageiro que sinalize, mesmo sendo suspeito para o motorista, ou burlar a regra e correr o risco de sofrer penalidades, até mesmo sua demissão.

O primeiro critério diagnóstico para o quadro de TEPT é a vivência pessoal direta ou indireta de um ou mais eventos estressores traumáticos extremos. Todos os rodoviários entrevistados relataram ter vivenciado, de forma direta, mais de um assalto no contexto de trabalho. Os assaltos são caracterizados predominantemente pela presença de arma, o que segundo os entrevistados, é um fator que contribui para o assalto tornar-se mais "traumatizante" ou "estressante", pois a integridade física do trabalhador encontra-se ameaçada.

O segundo assalto já foi mais estressante porque eles colocaram o revólver na minha cabeça e forçou e eu dirigindo, tentando olhar pra frente e eles me xingando (...) eu fiquei realmente abalado (...) e 'cê fica à mercê deles sem poder fazer nada porque eles estão armados (...) (Motorista 2).

Segundo o DSM-IV (2002), a resposta do indivíduo aos estressores traumáticos extremos é marcada por intenso medo, impotência ou horror. Os rodoviários foram unânimes ao relatar que, diante da ameaça de desaparecimento físico, sua resposta é de medo e, principalmente de impotência, pois a arma potencializa o "poder de controle" do assaltante e inibe o "poder de reação" do rodoviário.

O segundo critério diagnóstico para o quadro de TEPT é a revivência do "evento estressor traumático". Alguns sintomas que compõem o segundo critério diagnóstico para o quadro de TEPT podem ser identificados nos relatos dos rodoviários. Um dos sintomas é a revivência recorrente do evento traumático em pensamentos e imagens:

Fui assaltado em quatro dias, sete vezes. Eu não conseguia parar de pensar no assalto, me ocorreu uma dor cabeça, de excesso de pensamento (Cobrador 1).

Outro sintoma desse segundo critério que pode ser identificado é a revivência do assalto em sonhos aflitivos, presente no relato de um dos motoristas entrevistados:

Você até sonha que tá acontecendo alguma coisa porque pesa mesmo, o assalto não sai da cabeça, primeiros dias é pesado (Motorista 8).

Outro sintoma que compõe o segundo critério diagnóstico para o quadro de TEPT e que pode ser encontrado nos relatos dos rodoviários é o sofrimento psicológico decorrente do contato com indícios externos que simbolizam ou trazem a recordação de algum aspecto do trauma.

Um dos aspectos que caracterizam os assaltos aos ônibus da empresa é o fato dos assaltantes serem predominantemente jovens do sexo masculino, denominados pelos 
rodoviários de "ninjas". Quando esses passageiros "suspeitos" estão em pontos de determinados trechos do itinerário ou entram no ônibus, o rodoviário vivencia um sofrimento psicológico marcado por sentimentos como medo, preocupação e susto.

'Cê vê aqueles camaradinhas de boné, bermudão. A gente que já foi assaltado já fica meio apreensivo, já tem um pouco daquele medo (Motorista 5).

O sintoma de sofrimento psicológico no contato com indícios externos que simbolizam o trauma também pode ser identificado em outras situações vivenciadas pelos rodoviários durante a jornada de trabalho. Geralmente, o assaltante esconde a arma no bolso da jaqueta, da calça ou da bermuda. No momento do assalto, ele coloca a mão na cintura, tira a arma do bolso e aponta para o rodoviário.

Quando um passageiro "comum" coloca a mão no bolso para tirar o dinheiro da passagem, o rodoviário (mais especialmente o cobrador) vivencia um sofrimento psicológico caracterizado por susto e preocupação, pois esse movimento simboliza o aspecto do assalto "tirar a arma da cintura e apontar para o trabalhador":

Às vezes o cara levanta a camisa pra pegar a carteira cê já apavora. Já pensa que é arma. É aquela apreensividade, fica assustado (Cobrador 2).

O trecho da estrada onde ocorreu o assalto também é um indício externo que simboliza e traz a recordação do evento estressor traumático. Alguns rodoviários relatam um sofrimento psicológico caracterizado "pelo sentir medo" de retornar ao trecho onde aconteceu o assalto, principalmente nos primeiros dias após a sua ocorrência:

Os primeiros dias são terríveis, você fica preocupado em saber que vai ter que voltar ao lugar do assalto (...) (Motorista 2).

O terceiro critério diagnóstico para o quadro de TEPT é a evitação de estímulos que lembrem o evento traumático e o distanciamento de pessoas ou atividades significativas (não detectados antes do trauma). Durante a jornada de trabalho, alguns rodoviários, especialmente os motoristas, ao verem passageiros "suspeitos" dando sinal em determinados pontos do itinerário, fazem o que chamam de "janelar", isto é, não param o ônibus e deixam o passageiro para trás. Decisão que também coloca riscos de punição pela empresa contra o rodoviário que desacata as normas.

Quando vejo cara de bermudinha, cabelo amarelo, já janelo. Isso já aconteceu várias vezes comigo. Às vezes pode ser um assaltante, 'cê não vai parar pra ver (motorista 4).

O quarto critério diagnóstico para o quadro de TEPT engloba sintomas de excitabilidade acentuada (não detectados antes do trauma). Sintomas desse quarto critério diagnóstico podem ser identificados nos relatos dos rodoviários:

No dia do assalto 'cê não dorme, o tempo todo consegue relembrar direitinho o que aconteceu. Como se 'cê tivesse sendo assaltado de novo. Isso no primeiro dia é inevitável... (Motorista 8).

Eu fui assaltado, em sete dias, quatro vezes. Eu tava ficando estressado dentro de casa, a esposa, filho. 'Cê perde o controle (...), o tom de voz de quem tá estressando, o limite dele conversar é um, quando ele começa estressar, a voz dele vai aumentando, ele começa conversar gritando (Cobrador 1). 


\section{Considerações finais}

Diante do tema violência urbana e adoecimento psíquico dos profissionais de transporte coletivo, problematizamos a seguinte questão: qual a possibilidade de desenvolvimento de transtornos mentais em rodoviários de uma empresa da RMBH vítimas de assaltos no contexto de trabalho? A partir da análise dos dados coletados constatamos uma significativa correlação entre as experiências e os depoimentos dos rodoviários entrevistados e os sintomas que compõem o conjunto de critérios diagnósticos para o quadro de TEPT.

Os rodoviários vítimas de assaltos podem não apresentar um quadro de TEPT, porém, apresentam sintomas isolados desse quadro de transtorno mental e podem tornar-se vulneráveis ao desenvolvimento desse transtorno se continuarem expostos a assaltos, principalmente em situação de reincidência. Ressaltamos a presença de falas afirmativas em pelo menos um dos sintomas de cada critério diagnóstico que compõe o quadro de TEPT em todos os depoimentos dos sujeitos participantes do estudo. Também foi possível identificar no relato de um mesmo rodoviário, afirmações sobre experiências traumáticas em mais de um critério diagnóstico, fato que pode vir a confirmar um diagnóstico de TEPT.

É importante destacar que, durante o processo investigativo, os rodoviários trouxeram questões que extrapolam a problemática pesquisada, mas se apresentam como dados relevantes e correlacionados entre si. Uma das questões apontadas foi sobre a banalização do assalto, tanto pelo trabalhador, quanto pela empresa. O trabalhador, em uma tentativa de defesa do sofrimento psíquico resultante das recorrentes vivências de assalto no contexto de trabalho "acostuma-se" com a possibilidade de sua ocorrência. A empresa, por outro lado, considera o assalto como parte integrante da organização do trabalho do rodoviário, como uma situação frequente "nos dias de hoje", ou seja, o assalto torna-se associado a uma situação inevitável da nossa contemporaneidade.

Entretanto, o mecanismo de banalização e até mesmo de naturalização da violência pode causar sérias consequências para o trabalhador, como por exemplo, a não atenção devida aos riscos no trabalho e a formulação de estratégias de defesa durante a jornada de trabalho que paradoxalmente podem "ajudar a enfrentar o medo", como também podem ampliar a exposição aos riscos do assalto.

Os rodoviários da empresa pesquisada encontram-se expostos a um contexto de trabalho de alta periculosidade, invadido por frequentes episódios de assaltos que os tornam vulneráveis ao risco de desaparecimento físico. Diante da vivência desse risco real de morte, a maioria dos rodoviários entrevistados revelou que um trabalho que pode ser prazeroso tem se tornado um "fardo", suportado pela necessidade de sustento de suas famílias. Os rodoviários permanecem no emprego, mesmo com os riscos de violência e extermínio, por não verem outras possibilidades de emprego e renda.

Considerando o caráter essencial dos serviços de transporte coletivo no atendimento a uma das necessidades básicas da maioria da população que ocupa os centros urbanos, acreditamos que o impacto dos assaltos na saúde mental dos rodoviários merece a atenção de atores sociais envolvidos na prestação desse serviço de utilidade pública, quais sejam: a administração do transporte público (representada pelo DER) e da segurança pública (Polícia Militar), o setor privado (representado pela empresa pesquisada) e o sindicato da categoria.

A atuação integrada desses diferentes atores sociais pode ser o caminho resolutivo para o enfrentamento da realidade vivenciada pelos rodoviários pesquisados. Esse enfrentamento implica na elaboração e na implementação de políticas públicas e empresariais voltadas para a promoção da saúde e da segurança dos trabalhadores em transporte coletivo. Afinal, os rodoviários são trabalhadores que exercem uma função junto ao direito público de acesso e transporte da população. Acreditamos que uma proposta conjunta de intervenção público- 
privado pode minimizar ou reduzir a frequência de assaltos e concomitantemente seus impactos na saúde mental dos rodoviários e também da população usuária.

\section{Referências}

Almeida, N. D. V. (2002). Contemporaneidade x trânsito: reflexão psicossocial do trabalho dos motoristas de coletivo urbano. Psicologia Ciência e Profissão, 22 (3), 62-69.

BHtrans (2003). Transporte coletivo em Belo Horizonte. Disponível na internet: bhtrans.pbh.gov.br/bhtrans/transporte/transp_coletivo.asp [05 maio 2005]

Boschi, J. A. P. (2003). Violência e criminalidade: o resgate do pacto federativo como proposta de solução. Revista de Estudos Criminais, 3 (12), 156-167.

Caldeira, C. (2001). Assaltos a passageiros de ônibus no Rio de Janeiro: o problema da reparação de danos. Revista de Direito do Consumidor, 10 (38), 93-141.

Costa, L. B., Koyama, M. A. H., Minuci, E. G. \& Fischer, F. M. (2003). Morbidade declarada e condições de trabalho: o caso dos motoristas de São Paulo e Belo Horizonte. São Paulo em Perspectiva, 17 (2), 54-67.

Dejours, C. (1992). A loucura do trabalho: estudo de psicopatologia do trabalho (5⿳⺈ ed.). São Paulo: Cortez.

DSM-IV-TR (2002). Manual diagnóstico e estatístico de transtornos mentais (4⿳⺈-e ed.). Porto Alegre: Artmed.

Fundação João Pinheiro (1996). Ominibus: uma história dos transportes coletivos em Belo Horizonte. Belo Horizonte: Fundação João Pinheiro.

Fundação João Pinheiro (2005). Anuário de informações criminais de Minas Gerais. Belo Horizonte: Fundação João Pinheiro.

Mendes, L. R. (1999). O trabalho do motorista de ônibus: reflexões sobre as condições de trabalho no transporte coletivo. In J. D. Sampaio et al. (Orgs.), Qualidade de vida, saúde mental e psicologia social: estudos contemporâneos II (pp. 153-180). São Paulo: Casa do Psicólogo.

Morte de cobrador obriga PM a ir às ruas (2002, 8 de junho). O tempo, Belo Horizonte, caderno cidades, 9.

Paes-Machado, E. \& Levenstein, C. (2002). Assaltantes a bordo: violência urbana, insegurança e saúde no trabalho em transporte coletivo de Salvador, Bahia, Brasil. Cadernos de Saúde Pública, 18 (5), 1215-1227.

Waldvogel, B. C. \& Salim, C. A. (2002). Os motoristas e os acidentes de trabalho nas regiões metropolitanas de São Paulo e Belo Horizonte. In C. A. Salim \& L. F. Carvalho (Orgs.), Saúde e segurança no ambiente de trabalho: contextos e vertentes (pp. 25-41). Belo Horizonte: Fundacentro/Universidade Federal de São João Del Rey.

\section{Endereço para correspondência}

camilarsalves@hotmail.com, patriciapsi@pucminas.br 